\title{
Constitutional recognition: which way forward?
}

\author{
Damon Chester
}

University of Technology Sydney, Faculty of Arts and Social Sciences, PO Box 123, Ultimo NSW

2017, Australia.damon.chester@student.uts.edu.au

DOI: https://doi.org/10.5130/nesais.v4i1.1514

Though the topic is often evaded by mainstream news, the proposition of Indigenous constitutional recognition has been increasingly discussed within recent years and particularly so since the Aboriginal and Torres Strait Islander Peoples Recognition Act of 2013 was proposed under Prime Minister Julia Gillard. Several possible mechanisms for recognition have been proposed by government and Indigenous peoples, however the prevailing models to be fulfilled, if any, are yet to be known. In researching such mechanisms, I personally find myself to be confounded by the multiplicity of suggestions, complexity of needs from individual bodies, and the ramifications of enacting particular methodologies over others.

Prime Minister John Howard's minimalist approach based on 'mateship' and post-feminist ideologies of equality is a model I can reject, however. To do nothing towards achieving self-determination or sovereignty is to ignore systematic discrimination. His suggestion of introducing a preamble to the constitution acknowledging First Nations peoples is indeed an important symbolic gesture, though will achieve nothing of substance unless paired with real action.

The more recent Uluru Statement from the Heart instead offers more tangible and valuable objectives for progressing forward. By establishing a First Nations Voice in the Constitution and initiating a Makarrata Commission (Parliament of Australia 2017), wrongdoing can finally be recognised on a national scale with Indigenous bodies increasingly receiving a say in political matters. A 2015 survey conducted by IndigenousX found that $54 \%$ of Indigenous respondents supported the construction of such a parliamentary body with $62 \%$ believing that constitutional recognition would not be substantial in enacting change (Parliament of Australia 2017). Though I personally believe recognition within the constitution to be valuable, the large number of Indigenous people instead supporting the propositions of the Uluru Statement is telling. In saying this, the establishment of a First Nations Voice in parliament would require a referendum, just as the repealing of and insertion into sections of the Constitution would. The two models are not necessarily mutually exclusive and I do believe that if they were taken to referendum simultaneously, both may succeed in gathering support from a majority of Indigenous peoples as well as the wider Australian community.

Also aligning with the Uluru Statement, I feel as though initiating a Makarrata Commission or series of regional-level treaties with Indigenous nations could be the most effective mechanism for reducing 
paternalism. Regional or state-level treaties, as opposed to a nation-wide treaty, would allow for greater communication with individual nations and inclusion of their specific needs that could then be addressed to a parliamentary body as suggested by the Uluru Statement. Though treaties would not require a referendum, the establishment of such treaties should ideally be included within the same campaign aiming to enact constitutional recognition and an Indigenous parliamentary body to avoid being seen as competing models. Leading arguments against such models of recognition seem to stem from individuals believing that there exists a more effective method rather than outright opposition to each model individually (Langton 2013). While it is true that Indigenous peoples should not settle for a preamble or a treaty alone, action must start somewhere and I would like to believe that constructive change, no matter what form it comes in, will come soon.

\section{References}

Aboriginal and Torres Strait Islander Peoples Recognition Act 2013 (Cth).

Parliament of Australia 2017, Uluru Statement: a quick guide, viewed 29 May 2018, $<$ https://www.aph.gov.au/.../rp/rp1.../Quick_Guides/UluruStatement>.

Langton M. 2013, 'Indigenous Exceptionalism and the Constitutional 'Race Power'' in Space, Place \& Culture. 